\title{
Transport of iodide in structured clay-loam soil under maize during irrigation experiments analyzed using HYDRUS model
}

\author{
Agota Horel ${ }^{1 *}$, Lubomír Lichner ${ }^{2}$, Abdallah AlaOui ${ }^{3}$, Henryk CzaChor $^{4}$, Viliam NagY ${ }^{2}$ \\ \& Eszter TóTH ${ }^{1}$ \\ ${ }^{1}$ Soil Science and Agricultural Chemistry Institute, Hungarian Academy of Sciences, Herman Ottó út 15, H-1022 Budapest, \\ Hungary; e-mail: horel.agota@agrar.mta.hu \\ ${ }^{2}$ Institute of Hydrology, Slovak Academy of Sciences, Račianska 75, SK-83102 Bratislava, Slovakia; e-mail: \\ lichner@uh.savba.sk \\ ${ }^{3}$ Center of Development and Environment, Bern University, Bern, Switzerland; e-mail: Abdallah.Alaoui@cde.unibe.ch \\ ${ }^{4}$ Institute of Agrophysics, Polish Academy of Sciences, Doswiadczalna 4, PL-20236 Lublin, Poland; \\ e-mail: h.czachor@ipan.lublin.pl
}

\begin{abstract}
Transport of radioactive iodide ${ }^{131} \mathrm{I}^{-}$in a structured clay loam soil under maize in a final growing phase was monitored during five consecutive irrigation experiments under ponding. Each time, $27 \mathrm{~mm}$ of water were applied. The water of the second experiment was spiked with $200 \mathrm{MBq}$ of ${ }^{131} \mathrm{I}^{-}$tracer. Its activity was monitored as functions of depth and time with Geiger-Müller ( $\mathrm{G}-\mathrm{M})$ detectors in 11 vertically installed access tubes. The aim of the study was to widen our current knowledge of water and solute transport in unsaturated soil under different agriculturally cultivated settings. It was supposed that the change in ${ }^{131} \mathrm{I}^{-}$activity (or counting rate) is proportional to the change in soil water content. Rapid increase followed by a gradual decrease in ${ }^{131} \mathrm{I}^{-}$activity occurred at all depths and was attributed to preferential flow. The iodide transport through structured soil profile was simulated by the HYDRUS 1D model. The model predicted relatively deep percolation of iodide within a short time, in a good agreement with the observed vertical iodide distribution in soil. We found that the top $30 \mathrm{~cm}$ of the soil profile is the most vulnerable layer in terms of water and solute movement, which is the same depth where the root structure of maize can extend.
\end{abstract}

Key words: HYDRUS 1D model; infiltration; field tracer experiment; structured clay loam soil; preferential flow

\section{Introduction}

Water movement through terrestrial subsurface has a major role in agriculturally cultivated areas, as both water and minerals that are essential for achieving good crop growth can move below the root zone at different rates. In the meantime, climate change related threats and concerns to agriculture are growing worldwide. Many cultivated areas are experiencing increases in the frequency and intensity of heavy rains, which can be followed by long, dry, and hot spells (Hardy 2003; Faško et al. 2008). These changes can lead to preferential water flow, surface runoffs, and/or soil degradation such as erosion; therefore the quality of surface and groundwater can deteriorate (Onderka \& Pekárová 2008; Lichner et al. 2013; Farkas et al. 13). Solute leaching into the subsurface, e.g. different types of contaminants especially nitrogen or organic pollutants, can cause an adverse effect on the habitats of both soil microorganisms and plants (Horel \& Schiewer 2014; Mortazavi et al. 2013); therefore enhancing our knowledge on water and different solute transports through saturated and unsaturated subsurface is vital to mitigate any possibly harmful effects that might occur to soil ecosystems.

Water and solutes can move preferentially in soils containing macropores, bypassing much of the soil matrix (Beven \& Germann 2013). Preferential flow has a significant influence on water movement through the soil, especially in case of infiltration, drainage, and specifically on solute transport. These substantial effects of preferential flow via soil macropores and cracks on solute transport were observed in clay and clay loam soils by Dohnal et al. (2009). The authors investigated single- and dual-continuum data and found that cumulative infiltration rates can be as much as 5 times higher when dual-continuum measurements and simulation data were investigated compared to singlecontinuum (Dohnal et al. 2009). Heterogeneous soil matrices can generate non-equilibrium conditions between solute concentration and pressure head between preferential flow and soil matrix (Gerke 2006) resulting in solute partially entering the heterogeneous soil profile.

Several studies have been focusing on water and solute transport in heterogeneous and variably saturated soil matrices in the past several decades (Balashov et al. 2014; Harter \& Zhang 1999; Hardelauf et al. 2007;

* Corresponding author 
Twarakavi et al. 2010). Dušek et al. (2013) used the one-dimensional dual-continuum model S1D_Dual (Vogel et al.2010) for simulations of transport of radioactive iodide ${ }^{131} \mathrm{I}^{-}$in a black clay loam soil under spring barley in an early ontogenesis phase was monitored during controlled field irrigation experiment. It was found that iodide bound in the soil matrix could be mobilized by the surface leaching enhanced by mechanical impact of water drops and transported below the root zone of crops via soil cracks. It was found in another study by Vogel et al. (2007) that even cadmium sorbed on soil particles $<0.01 \mathrm{~mm}$ can be transported via soil macropores in sandy-loam soil up to the depth of $65 \mathrm{~cm}$.

Mathematical modeling of water and solute movement through unsaturated soil matrices can be useful tools to help understand the relationship between measured water or solute concentrations and soil physical properties. We used HYDRUS 1D model to simulate iodide movement in unsaturated soil columns. In the last several years, the HYDRUS models, such as single-porosity or dual-permeability models, have been used to estimate solute movements with high certainties to measured data for both saturated and unsaturated soil matrices (Kodesova et al. 2009). Pang et al. (2000) observed good correlations between measured and simulated pesticide concentrations in unsaturated soils based using HYDRUS 2D models. The authors also found that preferential flow could be responsible for fast contaminant leaching into the subsoil (Pang et al. 2000). Gardenas et al. (2006) compared the equilibrium, the dual porosity, and the dual-permeability models to measured data under tile-drained conditions and found that among the three models the dual permeability model had the best estimated values for preferential flow.

The aim of this study was to analyze the iodide transport through clay loam soil under maize during five consecutive irrigation experiments under ponding following long hot, dry period, and to better understand how water movement might affect nutrients and minerals leaching below the root zone. The present study was a part of a series of experiments with different agricultural crops of interest. The HYDRUS 1D software package (Simunek et al. 2007) was used for simulating the one-dimensional movement of water and iodide in structured clay loam soil. Model predictions of iodide transport were then compared with data from field irrigation experiment. The obtained results can help understand water, solutes or pollutants such as nutrient or pesticides leaching under maize cultivated agricultural fields. These results consequently can help mitigating some negative effects associated with the water/solute transportation process.

\section{Material and methods}

\section{Field experiment and soil}

The present study embraces one of four experiments done in the Experimental Station of the Research Institute of Irrigation Bratislava in 1993-1996. The study area is located in Most pri Bratislave village $\left(48^{\circ} 08^{\prime} 27^{\prime \prime} \mathrm{N}, 17^{\circ} 14^{\prime} 41^{\prime \prime} \mathrm{E}\right)$, and it is about $133 \mathrm{~m}$ above sea level. At the study site, the average annual air temperature is $9.7^{\circ} \mathrm{C}$ and the average annual precipitation amount is $554 \mathrm{~mm}$. Hourly and daily precipitation data during heavy rain events measured at two meteorological stations in the southwest of Slovakia were presented by Lichner et al. (2006). The soil is classified as a Chernozem (WRB 2006) and has a clay loam texture (Soil Survey Division Staff 1993). The soil profile consists of three relatively homogeneous horizons. Physical and chemical properties of the surface horizon were as follows: clay/loam/sand contents were $53 / 46 / 1 \%, \mathrm{CaCO}_{3}$ content $11.2 \%, \mathrm{C}_{\text {org }}$ content $1.9 \%, \mathrm{pH}\left(\mathrm{H}_{2} \mathrm{O}\right) 8.2$, and $\mathrm{pH}(\mathrm{KCl})$ 7.8. Particle size distribution, bulk density and saturated hydraulic conductivity in deeper depths at $0.1 \mathrm{~m}$ depth increment are presented in Alaoui et al. (1997).

The experiment was performed at a $1 \mathrm{~m} \times 1 \mathrm{~m}$ plot under maize (Zea mays L.) in a final growing phase. The maize stalks were cut prior to the experiment. Experimental conditions were similar to those described by Dusek et al. (2013). Concisely, a radioactive tracer technique developed by Lichner (1992) was used to measure the tracer distribution in the soil profile. The measuring probe, used to determine tracer concentrations, consists of a duralumin access tube (inner diameter of $8 \mathrm{~mm}$, outer diameter of $12 \mathrm{~mm}$ ), in which the Geiger-Müller detector (with the length of $21 \mathrm{~mm}$ and the diameter of $6.3 \mathrm{~mm}$ ) and the analog interface unit are connected to a nuclear analyzer with a coaxial cable. The counting rate recorded by the detector is directly proportional to the activity of the radioactive tracer (IAEA 1975), in this case to the mass of radioactive iodine occurring in a cylindrical volume with the radius of a few centimeters (the half-thickness of the contributing volume for the clay loam soil and ${ }^{131} \mathrm{I}$ is about $1 \mathrm{~cm}$ ). It was supposed that the change in ${ }^{131} \mathrm{I}^{-}$activity is proportional to the change in soil water content. Twelve probes were installed vertically to the depth of $1.5 \mathrm{~m}$ on the plot before the irrigation had started; however, only data from 11 probes were used in the present paper due to non-representativeness of soil properties at one of the probes. Exact instrumentation of the soil block is presented in Alaoui et al. (1997).

Five infiltration experiments, subsequently labeled run 1 to run 5 , were performed under ponding conditions by periodically and gently sprinkling $27 \mathrm{~mm}$ of water (in runs 1 , 3,4 , and 5) or iodide solution (in run 2) on the soil surface into the confined area of $1 \mathrm{~m} \times 1 \mathrm{~m}$. Water or iodide solution were applied manually with a watering can in small amounts such the ponding was maintained during infiltration and that its depth did not exceed a few millimeters. Times, durations and average rates of the five infiltration runs are presented in Alaoui et al. (1997). While the infiltration durations varied amongst experiments (i.e. run 1, 2, 3,4 , and 5 durations were 1630, 4800, 7440, 10500, and 9300 seconds, respectively; Alaoui et al. 1997), for simplification purposes during simulation, these durations were assumed to be equally 1 hour at each infiltration times (Fig. 1).

The soil-water retention curves for the three soil horizons were measured by standard pressure plate apparatus method on undisturbed soil samples and the hydraulic parameters were consequently obtained by fitting van Genuchten's modified prediction model (Vogel et al. 2000) to data points. The measurements of the saturated hydraulic conductivity $K_{\mathrm{s}}$ were carried out by tension infiltrometer at three depths. Five replicate measurements were conducted at each depth. The volumetric portion of the macropore or preferential flow $(\mathrm{PF})$ domain, $w_{\mathrm{f}}$, was 


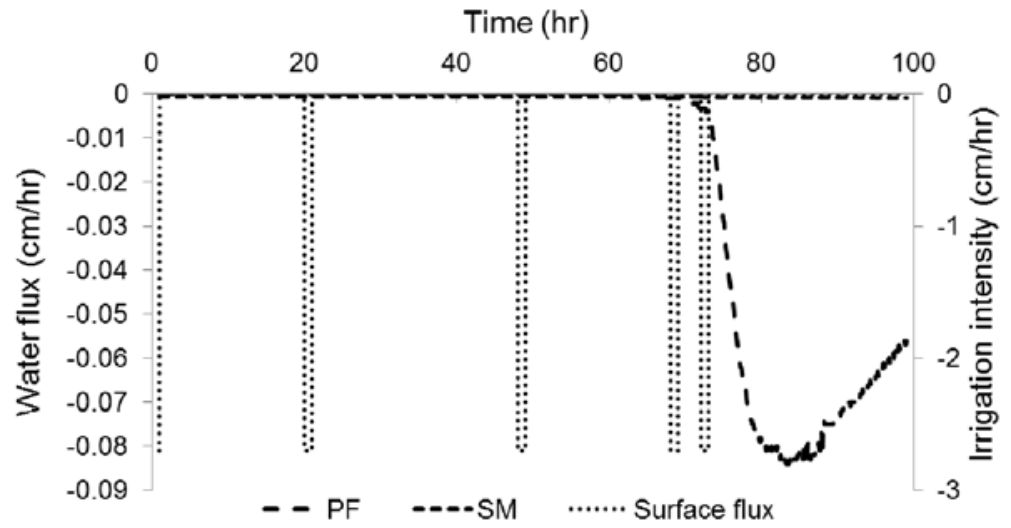

Fig. 1. Simulated vertical water flux distributions in the soil profile at the soil surface (secondary axis) and at the depth of $80 \mathrm{~cm}$ for the SM and PF flow domains (primary axis).

Table 1. Measured and estimated soil hydraulic properties. SM and PF refer to the soil matrix and preferential flow domain, respectively.

\begin{tabular}{|c|c|c|c|c|c|c|c|c|}
\hline Domain & $\begin{array}{l}\text { Depth } \\
(\mathrm{cm})\end{array}$ & $\left(\mathrm{cm}^{3}{ }^{\theta_{\mathrm{r}}} \mathrm{cm}^{-3}\right)$ & $\left(\mathrm{cm}^{3} \mathrm{~cm}^{-3}\right)$ & $\begin{array}{c}\alpha \\
\left(\mathrm{cm}^{-1}\right)\end{array}$ & $\begin{array}{c}n \\
(-)\end{array}$ & $\begin{array}{c}K_{\mathrm{s}} \\
\left(\mathrm{cm} \mathrm{d}^{-1}\right)\end{array}$ & $\begin{array}{c}h_{\mathrm{s}} \\
(\mathrm{cm})\end{array}$ & $\begin{array}{l}w_{\mathrm{f}} \\
(-)\end{array}$ \\
\hline \multirow[t]{3}{*}{$\mathrm{SM}$} & $0-55$ & 0.011 & 0.489 & 0.049 & 1.203 & 15.7 & -0.08 & 0.15 \\
\hline & $55-85$ & 0.011 & 0.491 & 0.028 & 1.296 & 15.6 & -0.16 & 0.15 \\
\hline & $85-100$ & 0.011 & 0.488 & 0.007 & 1.287 & 16.9 & -0.68 & 0.15 \\
\hline $\mathrm{PF}$ & $0-100$ & 0.050 & 0.600 & 0.145 & 2.680 & 700.0 & 0.00 & 0.15 \\
\hline
\end{tabular}

estimated as $15 \%$ of the bulk soil. The retention curve parameters of the $\mathrm{PF}$ domain were also estimated based on indirect soil and plot characteristics. The sensitivity of the dual-continuum model to uncertainties associated with preferential flow parameters was studied by Dohnal et al. (2012).

Water and solute flow and transport model

The HYDRUS 1D with two modules (single-porosity and dual-permeability) was used to simulate solute transport with the van Genuchten-Mualem hydraulic model. Although two sets of modules were run using HYDRUS 1D, in the present paper the main focus was given to the dualpermeability module, as it showed to be more representative to the field conditions at the presented experimental site.

The Richards' equation, which describes isothermal Darcian flow in a variably saturated rigid porous medium, was used in both models. While single Richards' equation is used in the case of the single-porosity model, in the dual-permeability model, which assumes that the porous medium consists of two separate domains with specific hydraulic properties. the Richards' equation is applied separately to each of the two pore regions, i.e. the macropore (fractures, larger pores) and matrix domains (Gerke \& van Genuchten 1993). Concepts of models for solute transport correspond to water flow models described above. The single convection-dispersion equation for solute transport is used for the single-porosity system. The dual-permeability formulation for solute transport was based on two convectiondispersion equations. In the present study, both set of hydraulic properties were modeled to simulate the solute flow through the soil matrices. The exchange of water and solute between the matrix and the fracture domains was assumed to be proportional to the local pressure difference and the concentration gradient between the two pore systems. The dual sets of governing equations for water flow and iodide transport were solved numerically with a finite element scheme using the HYDRUS 1D code (Simunek et al. 2007).
The geometry of the model depth was set to $110 \mathrm{~cm}$ where the first $80 \mathrm{~cm}$ had measured values available to compare simulation predictions, accordingly most results are presented for the upper $80 \mathrm{~cm}$ of the soil profile. Both, the single-porosity and dual-permeability models were used to simulate water flow within the soil profile with no hysteresis in the hydraulic model. Table 1 summarizes the soil hydraulic parameters for both SM and PF flow domains. $\theta_{\mathrm{r}}$ and $\theta_{\mathrm{s}}$ are the residual and saturated water contents, respectively, $h_{\mathrm{s}}$ is the air-entry value of Vogel et al. (2000), and $\alpha$ and $n$ are fitting parameters. Soil profile consisted of 3 layers (Table 1). In the case of the single-porosity model scenario single set of the van Genuchten (1980) soil hydraulic parameters with identical values as for SM domain's water flow parameters (Table 1) was applied for each layers. In the case of the dual-permeability scenario two sets (i.e. characteristics of soil matrix and macropore domain) of the van Genuchten (1980) soil hydraulic parameters for each layer were applied. The same macropore domain fraction $(w f=$ 0.15 ) was set for all layers. Soil physical values obtained in previous study by Dusek et al. (2013) were used. The following parameters describing water transfer between macropore and matrix domain (Gerke \& van Genuchten 1996) were applied: the dimensionless shape factor $\beta$ (describing aggregate shapes) was 15; the characteristic length of an aggregate was $0.1 \mathrm{~cm}$; the dimensionless scaling factor $\gamma$ was equal to 0.4 ; and the effective hydraulic conductivity $K_{\mathrm{a}}$ was 0.0157 , 0.0156 , and $0.0169 \mathrm{~cm} \mathrm{~d}^{-1}$, respectively, for the three soil profiles from top of the soil surface.

For solute transport, dispersivity value of $5 \mathrm{~cm}$ was used. The value of the molecular diffusion coefficient of iodide used in the present study was approximated to be $1.38 \mathrm{~cm}^{2} \mathrm{~d}^{-1}$ (presuming $18^{\circ} \mathrm{C}$ ) and was assumed to stay constant during the simulation period. The estimation was based on previous studies conducted by Trevani et al. (2000) where the authors investigated temperature dependent diffusion coefficients of iodide. Bulk density values of 

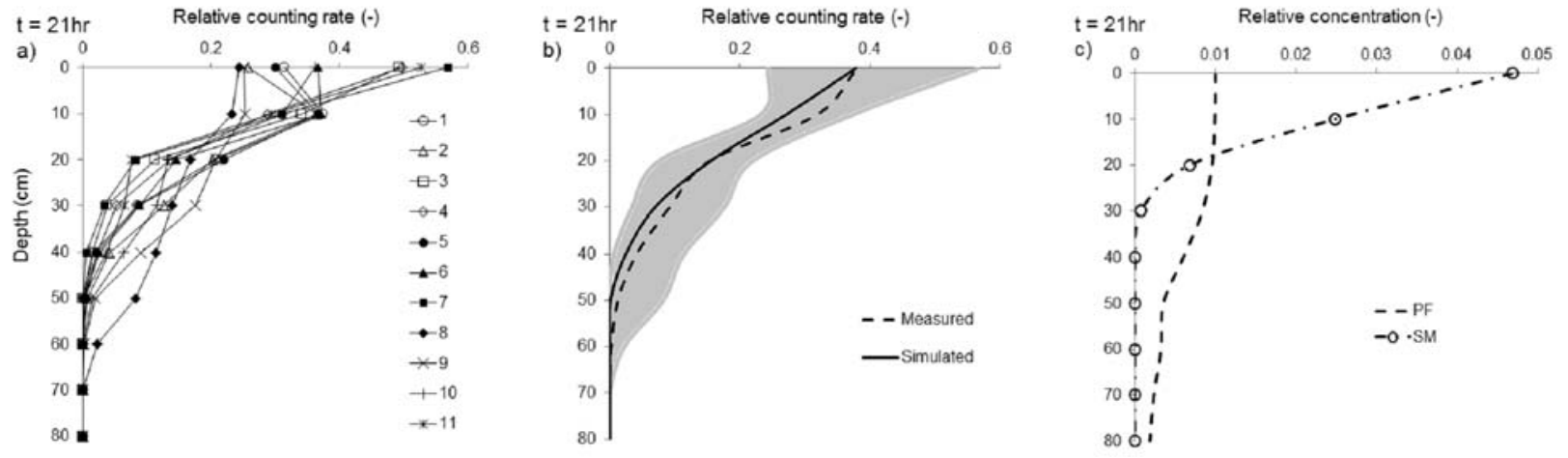

Fig. 2. Vertical iodide distributions in the soil profile: a) - measured iodide profiles along the individual probes for $t=21 \mathrm{~h}$ (infiltration of $27 \mathrm{~mm}$ of iodide solution); b) - simulated composite concentration and mean measured distribution with shaded area representing measurement variability among 11 probes; c) - simulated liquid concentrations in the flow domains.

$1.6 \mathrm{~g} \mathrm{~cm}^{-3}$ within the soil profile were used in the present study, which were taken from a previous study (Nováková 2000). The distribution coefficients were estimated based on a study done by Bird \& Schwartz (1996), where the authors found that clayey silty/sand sediment and sand sediments with low organic content had $K_{\mathrm{d}}$ values between $32 \pm 1.1$ and $0.1 \pm 2.7 \mathrm{~cm}^{3} \mathrm{~g}^{-1}$, respectively. Values in the present study for both the single-porosity and dual-permeability models $\left(K_{\mathrm{df}}=K_{\mathrm{dm}}\right)$ were set to equal $0.1 \mathrm{~cm}^{3} \mathrm{~g}^{-1}$ for all 3 layers.

In the case of the single-porosity model scenario the following parameters characterizing solute behavior were applied: longitudinal dispersivity was set to $0 \mathrm{~cm}$ for the upper 2 layers and to $11 \mathrm{~cm}$ for the $3^{\text {rd }}$ layer. The same parameters were applied in the matrix and macropore domain in the dual-permeability scenario. The solute transfer coefficient characterizing solute transfer between the mobile and immobile domains was set equal to $120 \mathrm{~cm}^{2} \mathrm{~d}^{-1}$.

Initial (IC) and boundary conditions (BC)

Measured iodide concentrations for solute and pressure heads for water flow prior to the experiment were used as initial conditions within the flow domain (in liquid phase concentration). The iodide tracer was applied under ponding conditions by periodically and gently sprinkling $27 \mathrm{~mm}$ of iodide solution (in run 2) on the wetted soil surface into the confined area of $1 \mathrm{~m} \times 1 \mathrm{~m}$, as described above.

The upper boundary condition was set at atmospheric BC with surface layer for both models. The water flow boundary conditions were set as free drainage at the bottom of the soil profile. The solute transport had the upper BC set as concentration $\mathrm{BC}$ to allow the tracer to pass freely to the lower boundary at the depth of $100 \mathrm{~cm}$ (Simunek et al. 2007) and zero concentration gradient for bottom BC. No rainfall had occurred for 14 days before the start of the infiltration experiment, so the initial soil water pressure was set to $-1200 \mathrm{~cm}$ throughout the entire soil profile for both the single- and dual-permeability models. No evapotranspiration was taken into account for the simulated period.

\section{Results and discussion}

The five infiltration experiments with the addition of $27 \mathrm{~mm}$ water at different time intervals to the soil surface is illustrated in Fig. 1 along with the simulated dual-permeability model water flux at $80 \mathrm{~cm}$ below the soil surface for the SM and PF soil matrices. It can be seen that during the first 50 hours into the experiment, the lower soil profile had minimal change in the water movement, while at later times, especially after the last infiltration experiment, both SM and PF matrices had significant modifications in the water fluxes (32.4$70.2 \%$ and $>400 \%$ for SM and PF, respectively; Fig. 1.). These results help to understand the solute movement through the heterogeneous soil profile at the different time periods explained below.

Observed and simulated vertical iodide distributions in the soil profile after irrigation of $27 \mathrm{~mm}$ of iodide solution in run 2 are shown in Fig. 2. During the first 21 hours in the experiment, all probes showed measurable iodide concentrations at $40 \mathrm{~cm}$ depth and some probes even could get iodide values at $60 \mathrm{~cm}$. Measurement variability among the 11 probes is clearly observable in Fig. 2a as each probe revealed a different transport path. The simulated average iodide concentrations in Fig. 2b show a deep infiltration, which is in reasonably good agreement with the observed distribution data. When comparing the two soil matrices with the separate hydraulic properties, the SM domain shows rapid decrease in the solute concentration at the first 21 hours of the experiment with relatively low values below $20 \mathrm{~cm}$ (Fig. 2c). In contrast, the PF domain has a significantly lower iodide concentration at the soil surface compared to SM domain, but the concentration by depth is much less pronounced. The distinct and sudden change at $55 \mathrm{~cm}$ could be attributed to the different hydraulic and soil properties of the separate PF soil layers (Table 1). Without considering preferential flow effects, iodide distribution was limited to the top $30 \mathrm{~cm}$ of the soil.

Observed and simulated vertical iodide distributions in the soil profile after irrigation of $27 \mathrm{~mm}$ of iodide solution in run 2 and $27 \mathrm{~mm}$ of water in run 3 are shown in Fig. 3. By the time the infiltration experiment reached 49 hours an additional $27 \mathrm{~mm}$ of water entered the system and the iodide concentrations could be measured at the depth of $70 \mathrm{~cm}$. Compared to the values measured at 21 hour, most individual probes showed less iodide concentrations at the soil surface than at $10 \mathrm{~cm}$ depth (Fig. 3a). Conversely, the 11 probes 

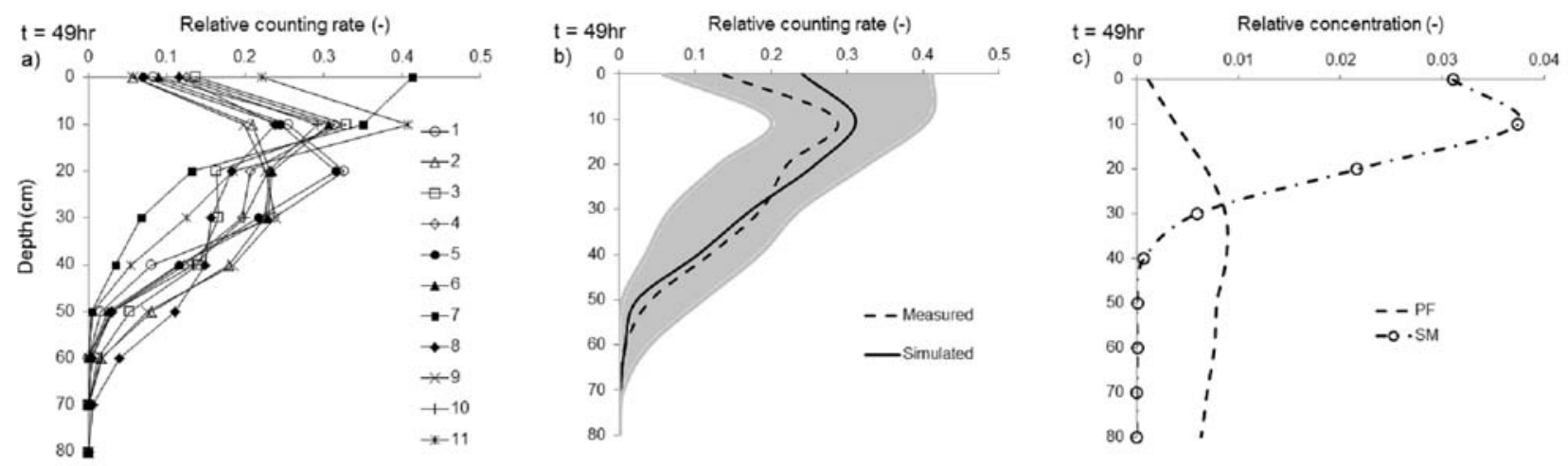

Fig. 3. Vertical iodide distributions in the soil profile: a) - measured iodide profiles along the individual probes for $t=49 \mathrm{~h}$ (infiltration of $27 \mathrm{~mm}$ of iodide solution $+27 \mathrm{~mm}$ of water); b) - simulated composite concentration and mean measured distribution with shaded area representing measurement variability among 11 probes; c) - simulated liquid concentrations in the flow domains.
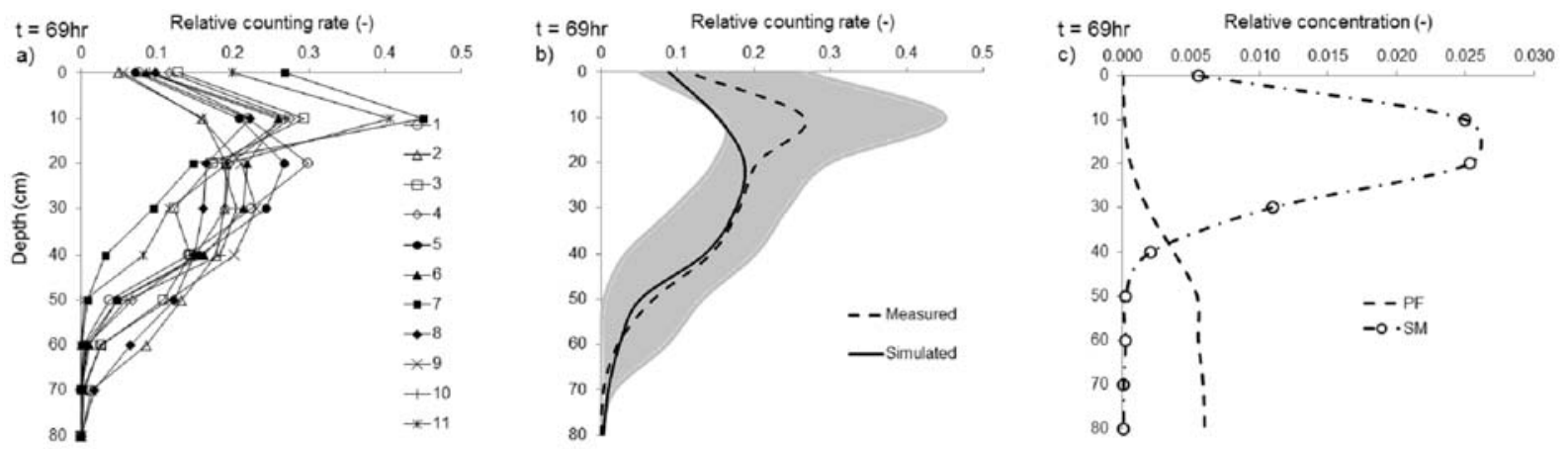

Fig. 4. Vertical iodide distributions in the soil profile: a) - measured iodide profiles along the individual probes for $t=69 \mathrm{~h}$ (infiltration of $27 \mathrm{~mm}$ of iodide solution $+54 \mathrm{~mm}$ of water); b) - simulated composite concentration and mean measured distribution with shaded area representing measurement variability among 11 probes; c) - simulated liquid concentrations in the flow domains.

showed high measurement variability at $10 \mathrm{~cm}$ depth, while the 21 hour data had relatively close concentration values at the same depth (Figs $2 \mathrm{a}$ and $2 \mathrm{~b}$ ). The simulated average iodide measurements in Fig. 3b also show a deep infiltration, in relatively good agreement with the observed distribution data. The simulated solute transport in the SM domain shows similar trends to the observed data for the upper $30 \mathrm{~cm}$ portion of the soil column, while below $30 \mathrm{~cm}$ no effects of iodide concentration can be seen (Fig. 3c). In contrast, the PF domain has a very low iodide concentration at the soil surface by 49 hours into the experiment; however the simulated values show a slight increase until the depth of 30-40 cm. Without considering preferential flow effects, iodide distribution was limited in the top $40 \mathrm{~cm}$ part of the topsoil.

Observed and simulated vertical iodide distributions in the soil profile after irrigation of $27 \mathrm{~mm}$ of iodide solution in run 2 and $54 \mathrm{~mm}$ of water in runs 3 and 4 are shown in Fig. 4. At 69 hours into the infiltration experiment the amount of irrigation was at the total of $81 \mathrm{~mm}$ including the $27 \mathrm{~mm}$ iodide solution. The measured iodide concentrations reached at the depth of $70 \mathrm{~cm}$, similar to the 49 hours data (Figs 3a and 4a). At this experimental time period no probes showed higher solute concentrations at the soil surface than values at $10 \mathrm{~cm}$, where the individual probes showed further increase in measurement variability (Fig. 4a). The simu- lated average iodide concentrations in Fig. 4b also show a deep infiltration; however, good agreement between the observed and simulated distribution data only can be seen deeper portions of the soil profile $(>20 \mathrm{~cm})$. In the top $20 \mathrm{~cm}$ of the soil matrix, the model simulation runs resulted in an underestimation of the solute concentration showing estimated values at the lower edge of the measured interval (Fig. 4b). Both the measured average and simulated solute transport in the SM domain shows similar trends to the observed data for the upper $30 \mathrm{~cm}$ portion of the soil column, while below $40 \mathrm{~cm}$ no effects of iodide concentration is visible (Fig. 4c). In contrast, the PF domain has a very low iodide concentration at the top $20 \mathrm{~cm}$ of the soil matrix with the simulated values showing an increase until the depth of $50 \mathrm{~cm}$, where the values seem to level out (Fig. 4c). Without considering preferential flow effects, iodide distribution was limited in the top $50 \mathrm{~cm}$ part of the topsoil.

Observed and simulated vertical iodide distributions in the soil profile after irrigation of $27 \mathrm{~mm}$ of iodide solution in run 2 and $81 \mathrm{~mm}$ of water in runs 3, 4, and 5 are shown in Fig. 5. Data observed at 73 hours into the experiment was similar to the 69 hour data where the overall infiltration amount was $27 \mathrm{~mm}$ less. All individual observation probes showed increase in iodide concentration from the soil surface to the $10 \mathrm{~cm}$ depth. Some probes even show to continue to 

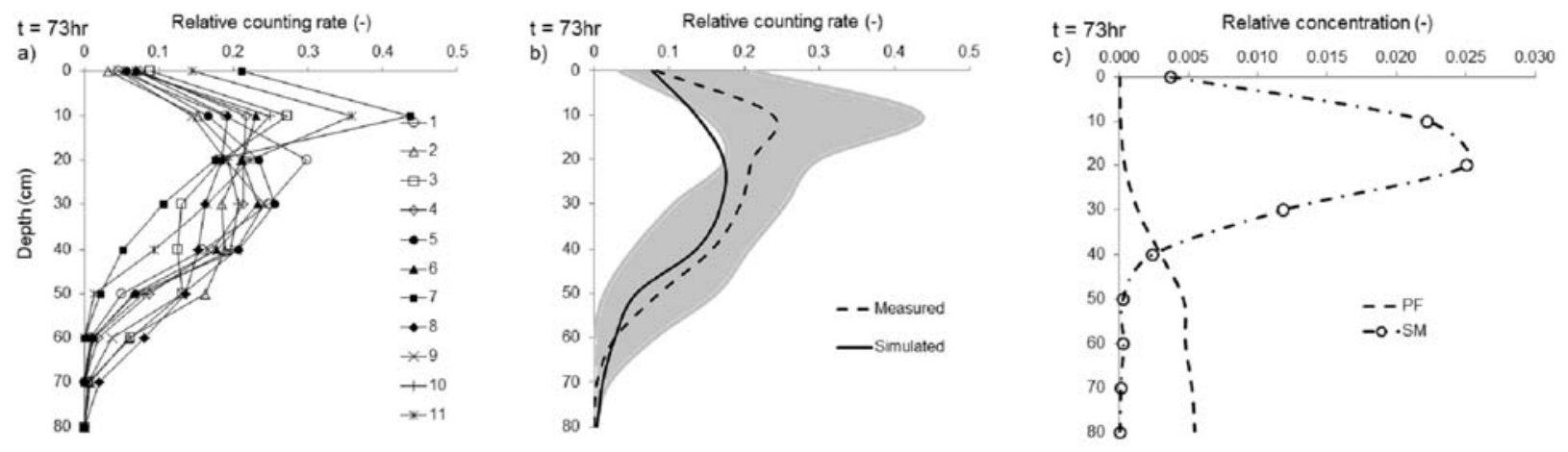

Fig. 5. Vertical iodide distributions in the soil profile: a) - measured iodide profiles along the individual probes for $t=73 \mathrm{~h}$ (infiltration of $27 \mathrm{~mm}$ of iodide solution $+81 \mathrm{~mm}$ of water); b) - simulated composite concentration and mean measured distribution with shaded area representing measurement variability among 11 probes; c) - simulated liquid concentrations in the flow domains.

this elevated concentration until the soil depth of $30 \mathrm{~cm}$ (Fig. 5a). However, when the average solute concentration is being evaluated (Fig. 5b), the model shows a less pronounced increase in the concentration amount for the first $20 \mathrm{~cm}$ depth than the measured data. Similar to previous observation time interval where $54 \mathrm{~mm}$ water addition was applied (Figs 4 and 5), the lower (below $30 \mathrm{~cm}$ ) soil profiles showed relatively good correlation between measured and simulated data. The measured average solute transport in the SM domain shows similar trends to the observed data for the upper $40 \mathrm{~cm}$ portion of the soil column, while below $50 \mathrm{~cm}$ no effects of iodide concentration are clearly visible (Fig. 5c). The $\mathrm{PF}$ domain has a low iodide concentration at the top $20-30 \mathrm{~cm}$ of the soil matrix with the simulated values showing an increase with depth (Fig. 5c).

Overall, at the beginning of the experiment, the simulated solute concentration follows particularly well the average measured values (Figs $2 \mathrm{~b}$ and $3 \mathrm{~b}$ ). However, at later times the model seems to slightly underestimate the solute amount at the upper $20 \mathrm{~cm}$ portion of the soil column (Figs 4b and 5b). At deeper depths, $30 \mathrm{~cm}$ and below, the measured and simulated concentration values well correlate again. This result can highlight the importance of the heterogeneity of the soil matrices where the experiment took place. Jarvis (2007) found that water pressure close to saturation can help generate non-equilibrium flow and water can bypass drier soil matrices, which further can support the substantial differences in iodide values between observation nodes (Figs 2a-5a). The differences between preferential flow and soil matrices greatly influenced the solute transport and water movement in the soil profile showing that the soil matrices affected only the top 20-40 cm of the soil surface. Gazis \& Feng (2004) found that it could take several months for precipitation to reach at soil below $40 \mathrm{~cm}$, which is comparable to the present findings. The single domain HYDRUS and the dual-permeability models were used by Gerke \& Kohne (2004) to investigated bromide leaching under tile-drained agricultural field conditions. The authors found that both models could simulate water movement through the soil relatively well; however, the dual permeability model could resulted a better approximation of the solute concentra- tion when compared to measured data (Gerke \& Kohne 2004). Similar study was done by Kodesova et al. (2005) where the authors investigated chlorotoluron transport through the soil profile. The study found that water regime has similar surface flux values for both models with major differences observed mostly in the bottom flux estimations. The solute transport models on the other hand showed that below the top $10 \mathrm{~cm}$ of the topsoil, the substrate concentrations differed substantially between models when matrix pores were investigated. In case of the dual-permeability model, the solute moved deeper into the soil profile compared to single permeability model. After a rapid decrease, an incline in concentrations were obtained in case of dualpermeability model (Kodesova et al. 2005). Similar increases, however much less pronounced, were observed in the present experiment (Figs 2c-5c) when the preferential flow and soil matrix were investigated.

Water movement through heterogeneous subsurface, amongst the above mentioned preferential flow and soil hydraulic properties, also can be influenced by evapotranspiration at the soil surface, which reduces the amount and the replenishment of soil water at deeper layers. In general, crop growth depends on the amount of precipitation. During long, dry periods or when evapotranspiration can exceed precipitation amount, irrigation can be a necessary choice of land management to avoid water stress and to ensure proper crop development (Farkas et al. 2005). However, it has been noted that during summer months the average evapotranspiration ranges between $2-5 \mathrm{~mm}$ (Liu et al. 2002), which in the present experimental conditions with cut down maize stalks should not be substantial and assumed to be negligible. Although during the present simulation evapotranspiration was not taken into account, it could be an important part of the water balance during the overall plant growing season. Similarly, the hydraulic conductivity $(K s)$ was measured and used this study based on given root structure from the location; however, it is important to note that root zones can additionally influence $K s$ values of the soil as found by Steudle (2000).

As the rooting depth of maize can hardly exceed $30 \mathrm{~cm}$ at the turn of April/May, it can be concluded 
that about $2 \%$ of iodide, bound in soil matrix and mobilized by the surface leaching enhanced by mechanical impact of water drops, could be transported below the root zone of crops via soil cracks after application of $100 \mathrm{~mm}$ water and the following $12 \mathrm{~h}$ redistribution period. It should be noted that $3 \mathrm{~h}$ precipitation of more than $127 \mathrm{~mm}$ was registered in this region e.g. on 10.7.1999; therefore the amount of water used in the present experiment can be representative for the location. The different rates of water and solute flow through the subsurface showed the importance of careful preparation of agricultural management systems. During intense precipitation events the leaching of nutrients that are important for crop growth can occur, while in more homogeneous soil matrices sufficient amount of fertilizer can be still available. Leaching ions through the soil profiles should be carefully analyzed, as Phillips \& Burton (2005) found a rapid leaching of surface applied fertilizer below the root depth and into the groundwater, resulting water pollution. Therefore, further study of water and solute movement in soils under different agricultural crops, plant growing phases, and soil cultivation techniques is necessary to further improve land management systems and lessen possible environmentally adverse effects associated with cultivation.

\section{Conclusions}

We can conclude that observed iodide distributions in the soil profile showed a relatively deep percolation within a short amount of time, which resulted in an underestimation of iodide concentration at upper soil layers. In the present experiment this upper soil layer extended to $30 \mathrm{~cm}$, which is approximately the same depth as the extent of maize root structure. The dual-permeability approach can allow a more adequate approximation of the field data, as leaching through macropores are expected under non homogeneous soil conditions. By using data for the soil matrix and also for the preferential flow in modeling proved to be a very useful tool for evaluation of field irrigation experiments conducted in structured soils. The present study helped to understand that preferential flow can substantially influence solute movement deeper into the subsurface, therefore allowing it to reach groundwater table at a faster rate compared to a homogeneous soil matrix. Conversely, further research should concentrate to couple modeled and measured data to advance different land management systems to support soil sustainability and to decrease possible soil degradation processes.

\section{Acknowledgements}

The authors thank the reviewer for valuable comments and recommendations. The research has been supported by the Scientific Grant Agency projects No. VEGA 2/0054/14 and VEGA 2/0083/11, as well as the Hungarian-Slovak Project No. MAD SNK 5/2013 - NKM 5/2014. This publication is the result of the project implementation ITMS 26240120004
Centre of excellence for integrated flood protection of land supported by the Research \& Development Operational Programme funded by the ERDF.

\section{References}

Alaoui A.M., Germann P., Lichner L. \& Novak V. 1997. Preferential transport of water and ${ }^{131}$ iodide in a clay loam assessed with TDR-technique and boundary layer flow theory. Hydrol. Earth Syst. Sci. 1: 813-822.

Balashov E., Buchkina N., Rizhiya E. \& Farkas Cs. 2014. Field validation of DNDC and SWAP models for temperature and water content of loamy and sandy loam Spodosols. Inter. Agrophysics 28: 133-142.

Beven K. \& Germann P. 2013. Macropores and water flow in soils revisited. Water Resour. Res. 49: 3071-3092.

Bird G.A. \& Schwartz W. 1996. Distribution coefficients, $\mathrm{K}_{\mathrm{d}} \mathrm{s}$, for iodide in Canadian shield lake sediments under oxic and anoxic conditions. J. Environ. Radioact. 35: 261-279.

Dohnal M., Dušek J., Vogel T., Císlerová M., Lichner L. \& Stekauerová V. 2009. Ponded infiltration into soil with biopores - field experiment and modeling. Biologia 64: 580-584.

Dohnal M., Vogel T., Šanda M. \& Jelínková V. 2012. Uncertainty analysis of a dual-continuum model used to simulate subsurface hillslope runoff involving oxygen-18 as natural tracer. J. Hydrol. Hydromech. 60: 194-205.

Dušek J., Lichner L', Vogel T. \& Štekauerová V. 2013. Transport of iodide in structured soil under spring barley during irrigation experiment analyzed using dual-continuum model. Biologia 68: 1094-1098.

Farkas C., Hagyo A., Toth E., Szabo J. \& Nemeth T. 2005. Evaluation of the soil water regime of an irrigated maize field. Acta Agron. Hung. 53: 161-175.

Farkas C., Beldring S., Bechmann M. \& Deelstra J. 2013. Soil erosion and phosphorus losses under variable land use as simulated by the INCA-P model. Soil Use and Manag. 29(s1): 124-137.

Faško P., Lapin M. \& Pecho J. 2008. 20-year extraordinary climatic period in Slovakia. Meteorol. Časopis 11: 99-105.

Gardenas A.I., Simunek J., Jarvis N. \& van Genuchten M.Th. 2006. Two-dimensional modelling of preferential water flow and pesticide transport from a tile-drained field. J. Hydrol. 329: $647-660$.

Gazis C. \& Feng X. 2004. A stable isotope study of soil water: evidence for mixing and preferential flow paths. Geoderma 119: $97-111$

Gerke H.H. 2006. Review Article. Preferential flow descriptions for structured soils. J. Plant Nutr. Soil Sci. 169: 382-400.

Gerke H.H. \& van Genuchten M.T. 1993. A dual-porosity model for simulating the preferential movement of water and solutes in structured porous media. Water Resour. Res. 29: 305-319.

Gerke H.H. \& Kohne J.M. 2004. Dual-permeability modeling of preferential bromide leaching from a tile-drained glacial till agricultural field. J. Hydrol. 289: 239-257.

Hardelauf H., Javaux M., Herbst M., Gottshalk S., Kasteel R., Vanderborght J. \& Vereecken H. 2007. PARSWMS: A parallelized model for simulating three-dimensional water flow and solute transport in variably saturated soils. Vadoze Zone J. 6: $255-259$.

Hardy J.T. 2003. Climate Change. Causes, Effects, and Solutions. Wiley, Chichester, 247 pp.

Harter T. \& Zhang D. 1999. Water flow and solute spreading in heterogeneous soils with spatially variable water content. Water Resour. Res. 35: 415-426.

Horel A. \& Schiewer S. 2014. Influence of inocula with prior hydrocarbon exposure on biodegradation rates of diesel, synthetic diesel, and fish-biodiesel in soil. Chemosphere109: 150156.

IAEA 1975. Laboratory Manual on the Use of Radiotracer Techniques in Industry and Environmental Pollution. Technical Reports Series no. 161. International Atomic Energy Agency, Vienna. 
Jarvis N.J. 2007. A review of non-equilibrium water flow and solute transport in soil macropores: principles, controlling factors and consequences for water quality. Eur. J. Soil Sci. 58: $523-546$.

Kodesova R., Kozak J., Simunek J. \& Vacek O. 2005. Single and dual-permeability models of chlorotoluron transport in the soil profile. Plant Soil Environ. 51: 310-315.

Kodesova R., Vignozzi N., Rohoskova M., Hajkova T., Kocarek M., Pagliai M., Kozak J. \& Simunek J. 2009. Impact of varying soil structure on transport processes in different diagnostic horizons of three soil types. J. Contam. Hydrol. 104: 107-125.

Lichner L'. 1992. Laboratory and field measurements of solute transport in soils by means of nuclear tracer technique. Vodohosp. Čas. 40: 548-561.

Lichner L., Dlapa P., Sir M., Cipakova A., Houskova B., Fasko P. \& Nagy V. 2006. The fate of cadmium in field soils of the Danubian lowland. Soil and Tillage Res. 85: 154-165.

Lichner L., Dušek J., Dekker L.W., Zhukova N., Faško P., Holko L. \& Śŕr M. 2013. Comparison of two methods to assess heterogeneity of water flow in soils. J. Hydrol. Hydromech. 61: 299-304.

Liu C., Zhang X. \& Zhang Y. 2002. Determination of daily evaporation and evapotranspiration of winter wheat and maize by large--scale weighing lysimeter and micro-lysimeter. Agr. Forest Meteorol. 111: 109-120.

Mortazavi B., Horel A., Anders J.S., Mirjafari A., Beazley M.J. \& Sobecky P.A. 2013. Enhancing the biodegradation of crude oil in sandy sediments with choline: a naturally methylated nitrogen compound. Env. Poll. 182: 53-62

Nováková K. 2000. Soil hydrophysical characteristics influencing rapid transfer of soluble contaminants, pp. 243-252. In: Heldi A. (ed.), Scientific papers of the Research Institute of Irrigation, Drainage and Landscape Engineering, Bratislava. (In Slovak)

Onderka M. \& Pekárová P. 2008. Retrieval of suspended particulate matter concentrations in the Danube River from Landsat ETM data. Science of the Total Environ. 397: 238-243.

Pang L., Close E.C., Watt J.P.C. \& Vincent K.W. 2000. Simulation of picloram, atrazine, and simazine leaching through two New Zealand soils and into groundwater using HYDRUS-2D. J. Contam. Hydrol. 44: 19-46.
Phillips I. \& Burton E. 2005. Nutrient leaching in undisturbed cores of an acidic sandy Podosol following simultaneous potassium chloride and di-ammonium phosphate application. Nutr. Cycl. Agroecosyst. 73: 1-14.

Simunek J., Jarvis N.J. \& van Genuchten M.Th. 2003. Review and comparison of models for describing non-equilibrium and preferential flow and transport in the vadose zone. J. Hydrol. 272: $14-35$.

Simunek J., Sejna M. \& van Genuchten M.Th. 2007. The HYDRUS software package for simulating the two- and threedimensional movement of water, heat, and multiple solutes in variably-saturated media. PC-Progress, Prague, Czech Republic.

Soil Survey Division Staff 1993. Soil survey manual. Soil Conservation Service. U.S. Department of Agriculture Handbook 18, 437 pp.

Steudle E. 2000. Water uptake by roots: effects of water deficit. J. Exp. Bot. WD Special issue. 51: 1531-1542.

Trevani L.N., Calvo E. \& Corti, H.R. 2000. Diffusion coefficients of iodide in high temperature aqueous solutions. Electrochem. Com. 2: 312-316.

Twarakavi N.K.C., Saito H., Šimůnek J. \& van Genuchten M.T. 2010. Inverse modeling of vadose zone flow processes using squared $\varepsilon$-insensitivity loss function. J. Hydrol. Hydromech. 58: $188-200$.

Vogel T., van Genuchten M.T. \& Císlerová M. 2000. Effect of the shape of soil hydraulic functions near saturation on variablysaturated flow predictions. Adv. Water Resour. 24: 133-144.

Vogel T., Lichner L., Dusek J. \& Cipakova A. 2007. Dualcontimuum analysis of a cadmium tracer field experiment. J. Contam. Hydrol. 92: 50-65.

Vogel T., Brezina J., Dohnal M. \& Dusek J. 2010. Physical and numerical coupling in dual-continuum modeling of preferential flow. Vadose Zone J. 9: 260-267.

WRB 2006. World reference base for soil resources 2006. 2nd edition. World Soil Resources Reports No. 103. FAO, Rome, $128 \mathrm{pp}$.

Received June 23, 2014 Accepted July 28, 2014 